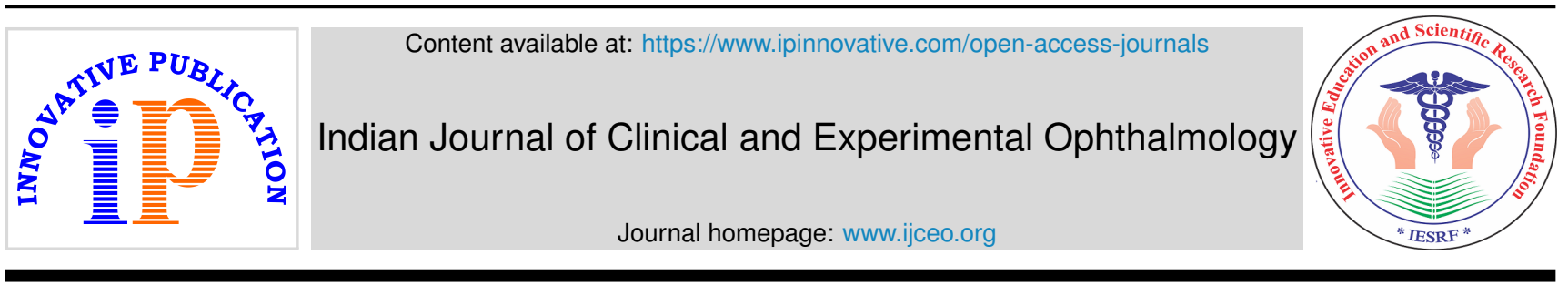

Original Research Article

\title{
A comparative study of the efficacy of preoperative loteprednol versus flurbiprofen in cataract surgery
}

\author{
Tek Chand ${ }^{1} *$, Arvind Chauhan ${ }^{1}$ \\ ${ }^{1}$ Dept. of Ophthalmology, Dr. S. N. Medical College, Jodhpur, Rajasthan, India
}

\section{A R T I C L E I N F O}

\section{Article history:}

Received 18-04-2020

Accepted 21-04-2020

Available online 22-12-2020

Keywords:

Flurbiprofen

Intraoperative mydriasis

Loteprednol

Postoperative complications

\begin{abstract}
A B S T R A C T
Purpose: To evaluate the efficacy and cost-effectiveness of preoperative loteprednol versus flurbiprofen, when combined with moxifloxacin in maintaining intraoperative mydriasis and reducing postoperative complications.

Materials and Methods: 200 cataract patients were divided into 2 groups. Group 1 receiving preoperative Flurbiprofen $(0.03 \%)$ with moxifloxacin $(0.5 \%)$ and Group 2 receiving Loteprednol $(0.5 \%)$ with moxifloxacin( $0.5 \%)$, three times a day $24 \mathrm{hrs}$ prior to cataract surgery,followed by postoperative loteprednol $(0.5 \%)$ and moxifloxacin $(0.5 \%)$ in both groups. Intraoperative mydriasis and post operative complications were analysed. Patients were followed up on day 1, 1 week, 3 weeks and 7 weeks. Parameters evaluated included inflammation, pain, corneal edema, anterior chamber reaction (including cells and flare), intraocular pressure, CME.

Results: Intraoperative mydriasis obtained in both the groups was comparable with no significant difference. Postoperative visual outcome was also comparable but postoperative inflammation was slightly more in Group $1(\mathrm{p}<0.05)$. Pain was more in group 1 on first postoperative day which was not statistically significant but this difference did not persist during further follow ups. 3 patients in group 1 and 2 patients in Group 2 developed CME on the last follow up which was not statistically significant. The rest of the parameters were comparable in the 2 groups with a much better compliance in group 2.

Conclusion: This hospital based study in western Rajasthan revealed Loteprednol to be equally potent as flurbiprofen in maintaining intraoperative mydriasis along with significant reduction of postoperative complications while maintaining cost effectiveness and compliance as a single eye drop was used before and after surgery, with no steroid related complications.
\end{abstract}

(C) This is an open access article distributed under the terms of the Creative Commons Attribution License (https://creativecommons.org/licenses/by/4.0/) which permits unrestricted use, distribution, and reproduction in any medium, provided the original author and source are credited.

\section{Introduction}

Cataract surgeries are frequently associated with postoperative ocular inflammation because of the tissue injury which releases prostaglandins from the uveal tissues. ${ }^{1}$ Prostaglandins (PGs) released in response to trauma following a surgical procedure which are mainly involved as the inflammatory mediators disrupt the Blood Aqueous Barrier (BAB), they produce changes in the intraocular pressure and cause intraoperative miosis. ${ }^{2}$ Most patients, therefore, experience some degree of postoperative

\footnotetext{
* Corresponding author.

E-mail address: drtcchahal@yahoo.com (T. Chand).
}

inflammation, pain, or both after the surgery. ${ }^{1}$

Nonsteroidal anti inflammatory drugs (NSAIDs) have become an important adjunctive tool for surgeons performing routine or complicated cataract surgery. These medications reduce pain, prevent intraoperative miosis, modulate postoperative inflammation, and reduce the incidence of cystoid macular edema (CME). Whether used alone, synergistically with steroids, or for specific high-risk eyes prone to the development of CME, the effectiveness of these medications is compelling. NSAIDs act by blocking the cyclooxygenase (COX) enzymes, COX-1 and COX-2, thereby reducing or blocking the production of prostaglandins. The potency of inhibition of 
COX-2 determines the clinical efficacy of the NSAID. ${ }^{2}$

Flurbiprofen is one of the commonly used NSAIDs for maintaining intraoperative mydriasis.

Cortiscosteroids are used routinely to prevent postoperative inflammation. Corticosteroids are thought to act by the induction of phospholipase A2 inhibitory proteins, collectively called lipocortins. It is postulated that these proteins control the biosynthesis of potent mediators of inflammation such as prostaglandins and leukotrienes by inhibiting the release of their common precursor arachidonic acid and by the same mechanism maintain pupillary dilatation but these steroids are associated with adverse reactions, like an increased Intraocular Pressure (IOP)-glaucoma, delay in wound healing, a decreased wound strength, ptosis, keratocyte apoptosis, corneal melting syndrome, crystalline keratopathy and the like. ${ }^{3}$

Loteprednol is designed to be active locally at the site of administration and then rapidly metabolized to inactive components after eliciting its actions at the desired location, thereby subsequently minimizing the chance for adverse effects. ${ }^{4}$

Hence, this prospective, interventional study was done to compare the efficacy and the tolerability of the topical steroid Loteprednol in the preoperative and postoperative period with the conventionally used topical NSAID Flurbiprofen in the preoperative period and loteprednol postoperatively in intraoperative mydriasis and postoperative outcomes.

\section{Materials and Methods}

\subsection{Study design}

The study was conducted as per the tenets of the Declaration of Helsinki after taking approval from the institutional ethics committee. It was a hospital based, prospective, interventional study. 200 patients visiting the outpatient department of Dr S. N. Medical College and associated hospitals, Jodhpur between September 2019 to January 2020 who fulfilled the inclusion criteria were enrolled in the study.

\subsection{Inclusion criteria}

1. Patients willing to give consent.

2. Age group $45-65 \mathrm{yrs}$.

3. Patients with grade 1 to 2 nuclear sclerosis.

\subsection{Exclusion criteria}

1. The patients with known / suspected allergy to the NSAIDs.

2. Patients having complicated cataract.

3. Pre-existing ocular inflammation.

4. Previous intraocular surgery.
5. The patients with uncontrolled systemic ailments such as Diabetes Mellitus, hypertension etc.

6. Known cases of glaucoma, corneal or retinal pathologies.

7. Congenital disorders such as corneal or retinal dystrophies, colobomas.

8. Patients with severe dry eye or other ocular surface disorders.

9. Patients with extensive corneal degenerative changes.

10. Patients with pseudoexfoliation syndrome.

11. Patients having corneal size $<11 \mathrm{~mm}$ or $>12 \mathrm{~mm}$.

12. Patients having developed intraoperative complications.

13. Patients with post operative vision less than 0.6 on the $\log$ MAR scale.

\subsection{Method of study}

A written informed consent was obtained from the participants after fully explaining to them, the procedure, its consequences and the right to withdraw at any point, in their own languages.

All patients after complete preoperative ophthalmological evaluation including visual acuity, ocular surface, extraocular and posterior segment evaluation underwent an evaluation for their grade of cataract on the basis of LOCS III (Lens Opacities Classification System) grading using slit lamp biomicroscope and were divided into 2 groups. ${ }^{5}$

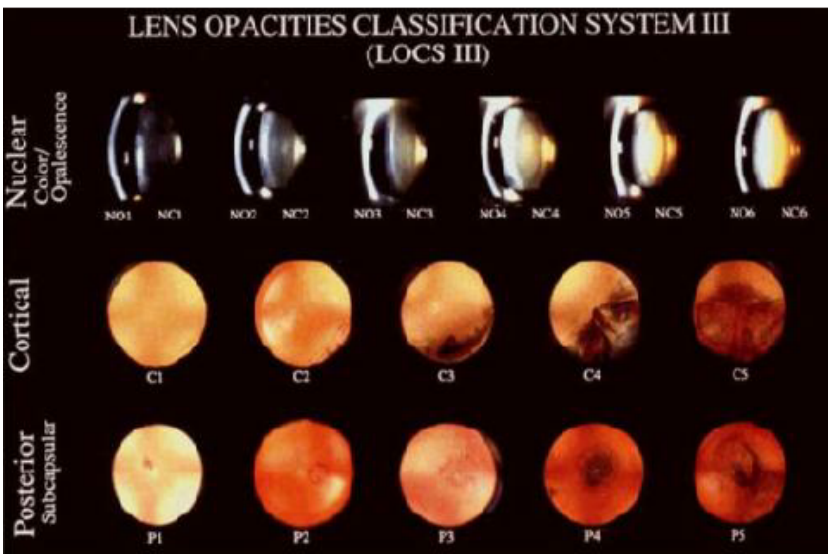

Fig. 1: LOCS grading

Group 1 patients were administered eye drop flurbiprofen $(0.03 \%)$ and moxifloxacin $(0.5 \%)$ whereas group 2 patients were administered Eye drop loteprednol $(0.5 \%)$ and moxifloxacin $(0.5 \%)$ by the instillation of 1 drop into the eye to be operated, 4 times a day 24 hours prior to surgery. Tropicamide eye drops $(1 \%)$ was used for all the patients preoperatively, 1-2 drops every 30 minutes for 2 hours. All patients underwent clear corneal temporal phacoemulsification on the Oertli (author don't have any 
Financial Interest) phaco machine by the same surgeon. The phaco parameters were kept constant for all cases wherein the power was $60 \%$, the aspiration flow rate was $34 \mathrm{ml} / \mathrm{min}$, and vacuum $350 \mathrm{~mm} \mathrm{Hg}$.

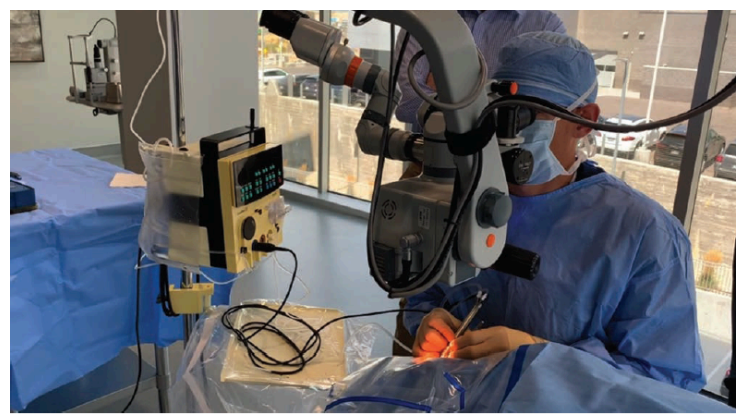

Fig. 2: Phaco machine and phacoimulsification procedure

Intraoperative mydriasis was measured in millimeters with the help of calipers prior to the corneal incision and at the end of the surgery.

Patients were instructed clearly on how to use the eye drops to ensure proper compliance and reduce wastage.

The patients were continued with eye drops loteprednol and moxifloxacin 6 times a day and were examined on the days - 1, 7, 28 and 45 after the surgery wherein the eye drops were gradually tapered on the second and third visit and stopped after the fourth visit. The following parameters were evaluated and graded.

\subsection{Visual acuity}

Using Snellen's visual acuity chart, and compared with the preoperative value

Persistent conjunctival inflammation was looked for and graded as: 6

1. Grade 0- None

2. Grade 1- Mild (some vessels injected)

3. Grade 2-Moderate (diffusely injected)

4. Grade 3- Severe (intense injection)

Corneal odema was graded as: ${ }^{6}$

1. On slit lamp biomicroscope

Grade 0 - cornea clear

Grade 1 - mild corneal edema in an area $<3 \mathrm{~mm}$

Grade 2 - moderate edema with iris details clear

Grade 3 - marked edema with iris details hazy

Grade 4 -intense edema covering more than half of the cornea with total obscuration of iris details

2. By measuring central corneal thickness and comparison with preop value

Anterior chamber reaction was looked for and graded as: ${ }^{7}$

Anterior chamber cells: (on slit lamp biomicroscope in an area of $1 \mathrm{~mm} \mathrm{2}$ )
Grade $0-<1$ cells

Grade $1-1-5$ cells

Grade 2 - 6- 15 cells

Grade 3 - 16 - 25 cells

Grade 4 - 26 - 50 cells

Grade 5 - >50 cells

Aqueous flare

Grade 0 - no flare

Grade 1 - faint (barely detectable)

Grade 2 - moderate (iris and lens details clear)

Grade 3 - marked (iris and lens details hazy)

Grade 4 - intense (fixed coagulated aqueous humor with considerable fibrin)

\subsection{Analgesia ${ }^{8}$}

The analgesia was graded by the patient's subjective assessment of the post-operative pain/discomfort by using a visual analogue scale (VAS) which was graded as 0-10, where $0=$ no pain and $10=$ worse imaginable pain.

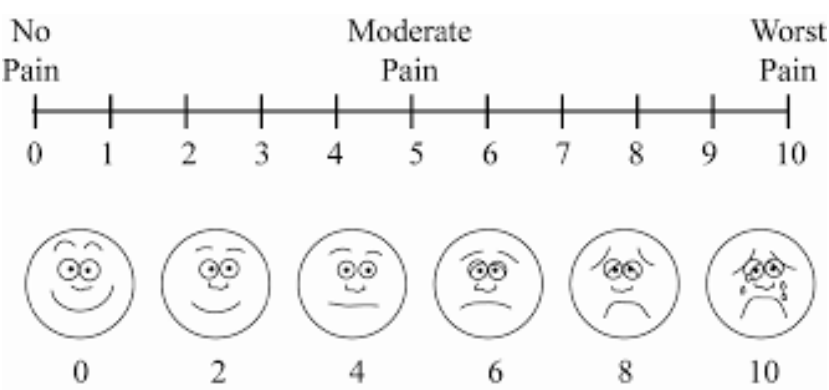

Fig. 3: Visual analogue scale for pain grading

Postoperative Intraocular pressure was measured and compared with the preoperative value using non contact tonometry

Fundus was evaluated on every visit using $90 \mathrm{D}$ lens to look for cystoid macular edema or any other complications.

\section{Results}

At the end of the study, data was analysed for 200 eyes of 200 patients included in the study.

The demographic characteristics: the mean age of the pooled patient population was $59.55+5.33$, the groups were age matched (with $\mathrm{P}=0.304$ ) and the gender distribution was statistically similar between the groups (with $\mathrm{P}=0.128$ ).

The study parameters like aqueous flare, cells in the anterior chamber and corneal oedema were of mild grade as has been depicted in the table, which subsided by visit 4 and were statistically comparable in both the groups. Whereas, the conjunctival inflammation persisted up to visit 4 in a mild form in both the groups, more in group 1 and was statistically significant, as has been depicted in the table.

The intraoperative mydriasis obtained in both the groups was comparable. 
Table 1: Comparison of post operative visual acuity in the 2 groups

\begin{tabular}{lccc}
\hline & Group I $(\mathbf{n}=\mathbf{1 0 0})$ & Group II $(\mathbf{n}=\mathbf{1 0 0})$ & P value \\
BCVA & & & 0.65 \\
Visit 1 & $0.2 \pm 0.2$ & $0.1 \pm 0.2$ & 0.65 \\
Visit 2 & $0.2 \pm 0.2$ & $0.1 \pm 0.2$ & 0.95 \\
Visit 3 & $0.1 \pm 0.1$ & $0.1 \pm 0.1$ & 0.96 \\
Visit 4 & $0.0 \pm 0.1$ & $0.0 \pm 0.1$ & \\
\hline
\end{tabular}

Table 2: Comparison of post operative anterior chamber cells in the 2 groups

\begin{tabular}{|c|c|c|c|c|c|c|c|c|c|c|c|c|c|}
\hline \multirow{3}{*}{$\begin{array}{l}\text { Anterior } \\
\text { chamber } \\
\text { cells }[\mathrm{n}= \\
100]\end{array}$} & \multicolumn{6}{|c|}{ Group 1} & \multicolumn{6}{|c|}{ Group 2} & \multirow[t]{3}{*}{ p value } \\
\hline & Grade & Grade & Grade & Grade & Grade & Grade & Grade & Grade & Grade & Grade & Grade & Grade & \\
\hline & 0 & 1 & 2 & 3 & 4 & 5 & 0 & 1 & 2 & 3 & 4 & 5 & \\
\hline Visit 1 & 65 & 21 & 14 & - & - & - & 67 & 22 & 11 & - & - & - & 0.81 \\
\hline Visit 2 & 69 & 20 & 11 & - & - & - & 71 & 19 & 10 & - & - & - & 0.95 \\
\hline Visit 3 & 91 & 9 & - & - & - & - & 93 & 7 & - & - & - & - & 0.61 \\
\hline Visit 4 & 96 & 4 & - & - & - & - & 97 & 3 & - & - & - & - & 0.74 \\
\hline
\end{tabular}

Table 3: Comparison of post operative aqueous flare in the 2 groups

\begin{tabular}{|c|c|c|c|c|c|c|c|c|c|c|c|}
\hline \multirow{2}{*}{$\begin{array}{l}\text { Aqueous } \\
\text { flare [n } \\
=100]\end{array}$} & \multicolumn{5}{|c|}{ Group 1} & \multicolumn{5}{|c|}{ Group 2} & \multirow[t]{2}{*}{ p value } \\
\hline & $\begin{array}{c}\text { Grade } \\
0\end{array}$ & $\begin{array}{c}\text { Grade } \\
1\end{array}$ & $\begin{array}{c}\text { Grade } \\
2\end{array}$ & $\begin{array}{c}\text { Grade } \\
3\end{array}$ & $\begin{array}{c}\text { Grade } \\
4\end{array}$ & $\begin{array}{c}\text { Grade } \\
0\end{array}$ & Grade 1 & Grade 2 & Grade 3 & Grade 4 & \\
\hline Visit 1 & 69 & 20 & 11 & - & - & 70 & 21 & 9 & - & - & 0.89 \\
\hline Visit 2 & 73 & 19 & 8 & - & - & 75 & 18 & 7 & - & - & 0.94 \\
\hline Visit 3 & 94 & 6 & - & - & - & 95 & 5 & - & - & - & 0.75 \\
\hline Visit 4 & 96 & 4 & - & - & - & 97 & 3 & - & - & - & 0.70 \\
\hline
\end{tabular}

Table 4: Comparison of post operative corneal edema in the 2 groups

\begin{tabular}{|c|c|c|c|c|c|c|c|c|c|c|c|}
\hline \multirow{2}{*}{$\begin{array}{l}\text { Corneal } \\
\text { edema [n } \\
=100]\end{array}$} & \multicolumn{5}{|c|}{ Group 1} & \multicolumn{5}{|c|}{ Group 2} & \multirow[t]{2}{*}{ p value } \\
\hline & $\begin{array}{c}\text { Grade } \\
0\end{array}$ & $\begin{array}{c}\text { Grade } \\
1\end{array}$ & $\begin{array}{c}\text { Grade } \\
2\end{array}$ & $\begin{array}{c}\text { Grade } \\
3\end{array}$ & $\begin{array}{c}\text { Grade } \\
4\end{array}$ & Grade 0 & $\begin{array}{c}\text { Grade } \\
1\end{array}$ & $\begin{array}{c}\text { Grade } \\
2\end{array}$ & Grade 3 & Grade 4 & \\
\hline Visit 1 & 71 & 23 & 6 & - & - & 77 & 20 & 3 & - & - & 0.48 \\
\hline Visit 2 & 74 & 19 & 7 & - & - & 75 & 17 & 8 & - & - & 0.91 \\
\hline Visit 3 & 95 & 5 & - & - & - & 97 & 3 & - & - & - & 0.47 \\
\hline Visit 4 & 99 & 1 & - & - & - & 100 & - & - & - & - & 0.91 \\
\hline
\end{tabular}

Table 5: Comparison of post operative conjunctival inflammation in the 2 groups

\begin{tabular}{|c|c|c|c|c|c|c|c|c|c|}
\hline \multirow{2}{*}{$\begin{array}{l}\text { Conjunctival } \\
\text { inflammation } \\
{[n=100]}\end{array}$} & \multicolumn{4}{|c|}{ Group 1} & \multicolumn{4}{|c|}{ Group 2} & \multirow[t]{2}{*}{ p value } \\
\hline & Grade 0 & $\begin{array}{c}\text { Grade } \\
1\end{array}$ & Grade 2 & Grade 3 & Grade 0 & Grade 1 & Grade 2 & Grade 3 & \\
\hline Visit 1 & 61 & 23 & 14 & 2 & 72 & 24 & 3 & 1 & 0.03 \\
\hline Visit 2 & 68 & 19 & 13 & - & 70 & 21 & 9 & - & 0.65 \\
\hline Visit 3 & 92 & 8 & - & - & 97 & 3 & - & - & 0.12 \\
\hline Visit 4 & 97 & 3 & - & - & 99 & 1 & - & - & 0.31 \\
\hline
\end{tabular}


Table 6: Comparison of post operative pain in the 2 groups

\begin{tabular}{lccc}
\hline Pain & Group 1 & Group 2 & P value \\
Visit 1 & $4.46 \pm 0.88$ & $4.56 \pm 0.75$ & 0.704 \\
Visit 2 & $2.12 \pm 0.95$ & $1.36 \pm 0.80$ & 0.053 \\
Visit 3 & $0.91 \pm 0.54$ & $0.66 \pm 0.58$ & 0.389 \\
Visit 4 & $0.25 \pm 0.44$ & 0 & - \\
\hline
\end{tabular}

There was no significant difference seen in the intraocular pressure (IOP) from the preoperative value in both the groups till the last visit.

3 patients in group 1 and 2 patients in Group 2 developed CME on the final visit which was not statistically significant.

The subjective parameter, ocular pain, as was assessed by using VAS, was present mostly till visit 3 and it was slightly more in group 1 which was not statistically significant as depicted in the table.

All the patients in Group 2 showed good compliance whereas 4 patients in Group 1 were not fully compliant, 2 out of which continued instilling Flurbiprofen eye drops postoperatively. All medications were well tolerated and no serious adverse reactions to any medication were reported.

\section{Discussion}

Maintaining intraoperative mydriasis is an imperative concern during cataract surgery and is of utmost importance for the completion of an uneventful surgery. Appropriate mydriasis is usually achieved by topical and/or intracameral administration of anticholinergic agents, sympathomimetic agents, or both, with the most commonly used being cyclopentolate, tropicamide, and phenylephrine. Ocular inflammation is common after cataract surgery. Topical steroids and nonsteroidal anti-inflammatory drugs are widely used because they have been proved effective to control postsurgical inflammation and decrease pain. Topical nonsteroidal anti-inflammatory drugs have also been shown to help maintain dilation. However, use of multiple preoperative drops for pupil dilation, inflammation, and pain control have been shown to be time consuming, cost ineffective and a cause for patient non compliance. ${ }^{9}$

The steroidal anti-inflammatory agents include natural, semisynthetic and synthetic glucocorticoids with powerful and nonspecific anti-inflammatory and immunosuppressant actions which result as the overall consequence of multiple mechanisms of action, which are mediated through specific intracellular receptors, which modulate the gene expression and affect all the components of the inflammatory and the immune responses. ${ }^{10}$ These are seen as, a reduction in the recruitment and the activation of the inflammatory cells, a decrease in the release of various cytokines (ILs, IFNs, TNF $\alpha$, PAF, etc.), inhibition of phospholipase A2 by inducing lipocortin synthesis, a decrease in the synthesis of arachidonic acid and its derivative mediators (PGs and
LTs), a decrease in the expression of COX-2 and NOS2 , a decrease in the synthesis of the adhesion molecules (ElLAM-1, ICAM-1) and a decrease in the T-lymphocyte activation and proliferation.

Glucocorticoids are readily absorbed from the cornea, conjunctiva and the sclera. However, the ocular penetration of the steroids occurs mainly through the cornea and it depends upon the relative water and the lipid solubility and the particle size, their concentrations, viscosity, $\mathrm{pH}$ and tonicity, the presence of other additives (adjuvants, preservatives-methylcellulose, etc), and the condition of the corneal epithelium. ${ }^{11}$

The ocular adverse effects of the steroids depend upon the dose and the duration of the steroid therapy, the potency of the steroid, the underlying disease states and the patient susceptibility.

The steroid induced/related ocular adverse effects and the complications include; increased Intraocular Pressure (IOP)-glaucoma, a delay in/retardation of the wound healing, a decreased wound strength, an increased susceptibility for infections, mydriasis, ptosis, keratocyte apoptosis, corneal melting syndrome, scleral staphyloma, crystalline keratopathy. ${ }^{11,12}$

Loteprednol, a 'soft' steroid, is less likely to cause steroid related ocular complications, while preserving the useful anti-inflammatory action. Loteprednol is an ester glucocorticoid with a $17-\beta$ chloro-methyl ester group and it is rapidly de-esterified to inactive the metabolites in the corneal tissue. ${ }^{13}$ Hence, it produces lesser systemic adverse effects.

Hence, we compared the efficacy of the soft steroid loteprednol in maintaining intraoperative mydriasis owing to its prostaglandin inhibitory effect along with preventing postoperative inflammatory complications, with the conventionally used NSAID flurbiprofen.

The anti-inflammatory action of the NSAIDs is primarily due to the inhibition of the cyclooxygenase enzyme (COX-1 and COX-2) and due to a decrease in the biosynthesis and the release of the proinflammatory PGs$\mathrm{PGE}_{2}, \mathrm{PGF}_{2 \alpha} \quad \mathrm{PGD}_{2}$ and $\mathrm{PGI}_{2} \cdot{ }^{14}$ Additional mechanisms like suppressing the leukocyte motility and chemotaxis, inhibiting the inflammatory cytokines and the free radical scavenging activity, may also contribute to their antiinflammatory action. ${ }^{2}$

Topical NSAIDs like flurbiprofen, ketorolac, bromofenac and diclofenac have previously been evaluated for their antiinflammatory actions and the prevention of intraoperative 
miosis and cystoid macular oedema. ${ }^{15}$

However, steroids being powerful anti-inflammatory agents, should be preferred in the patients with a severe form of the postoperative inflammation and in patients with complications.

There have been studies comparing the anti inflammatory action of NSAID's and low potency steroids in the postoperative period. In a study conducted by Abessi et al wherein they compared the efficacy of Difluprednate $0.05 \%$ and Loteprednol Gel 0.5\% After Cataract Surgery, they found that the anti inflammatory action of both loteprednol and difluprednate was comparable in uncomplicated cases. ${ }^{16}$ Similarly in a meta analytical survey conducted by Duan P et al., they concluded that topical NSAID's were effective in controlling postoperative anterior chamber inflammation. ${ }^{17}$ In a study on an Indian population conducted by Bannale et al., to compare Efficacy and the Safety of Topical Loteprednol

Etabonate and Topical Flurbiprofen Sodium in Patients with Post-Operative Inflammation after Cataract Extraction, the results were comparable. ${ }^{2}$

No study has been conducted in the Indian population exploring the role of steroids in intraoperative mydriasis, owing to their inhibitory action on prostaglandins.

Hence our study was aimed at minimizing the use of multiple medications in rural Indian population in western Rajasthan and thus improving compliance by using a single combination of moxifloxacin and loteprednol preoperatively to maintain mydriasis as well as postoperatively to prevent inflammation. As our study did not include patients with non dilating pupils and complicated cataracts, hence further evaluation is necessary to establish the role of loteprednol $0.03 \%$ as a safe and effective medication for intraoperative mydriasis as well as for prevention of postoperative inflammation.

\section{Conclusion}

We conclude that the use of loteprednol as a single agent preoperatively for mydriasis during phacoemulsification surgeries as well as for prevention of postoperative inflammation is a novel technique with comparable results to the use of flurbiprofen preoperatively and loteprednol postoperatively, with no steroid related complications and with better compliance and cost effectiveness, specially for illiterate and rural patients.

\section{Source of Funding}

None.

\section{Conflicts of Interest}

None.

\section{References}

1. Soon-Phaik C, Seng-Ei T, Meenakshi S, Donald TH. The post-operative inflammation: extracapsular cataract extraction versus phaco-emulsification. J Cataract Surg. 1995;25:1280-5.

2. Sihota R, Tondon R. Parson's Diseases of the Eye. 20th ed. Noida (India: Elsevier; 2008.

3. Simone JN, Pendelton RA, Jenkins JE. Comparison of the efficacy and safety of ketorolac tromethamine $0.5 \%$ and prednisolone acetate $1 \%$ after cataract surgery. J Cataract Refract Surg. 1999;25(5):699704. doi:10.1016/s0886-3350(99)00023-1.

4. Bannale SG. A prospective, open-label study to compare the efficacy and the safety of topical loteprednol etabonate and topical flurbiprofen sodium in patients with post-operative inflammation after cataract extraction. J Clin Diagn Res. 2012;6(9):1499. doi: $10.7860 / \mathrm{jcdr} / 2012 / 4759.2543$

6. Druzgala P, Wu WM, Bodor N. Ocular absorption and distribution of loteprednol etabonate, a soft steroid, in rabbit eyes. Curr Eye Res. 1991;10(10):933-7. 101:103109/02 / 368900020329.

7. Chylack LT, Wolfe JK, Singer DM, Leske MC, Bullimore MA, Bailey IL, et al. 1993.

8. Manjoo SR, Suneetha N, Reji KT, Batt RR. Topical diclofenac sodium for the treatment of postoperative inflammation. Drugs 2007;67(9):1291-308.

9. Nussenblatt RB, Whitcup SM. Examination of the patients with uveitis. In: Uveitis Fundamentals and Clinical Practice. Mosby; 2004. p. $54-65$.

10. Deloach LJ, Higgins MS, Caplan AB, Stiff JL. The visual analog scale in the immediate postoperative period: the intrasubject variability and the correlation with a numerical scale. Anesth Analg. 1998;86:102-6.

11. Gonzalez-Gonzalez L, Grob S, Daly M. Management of mydriasis and pain in cataract and intraocular lens surgery: review of current medications and future directions. Clin Ophthalmol. 2014;8:1281. do1:10.2147/opth.s4/569.

12. Dchimmer BP. Adrenocorticotropic hormone; adrenocortical steroids and their synthetic analogs; inhibitors of the synthesis and actions of adrenocortical hormones. In: Goodman \& Gilman's the pharmacological basis of therapeutics; 1996. p. 1466.

13. McGhee CNJ, Dean S, Danesh-Meyer H. The locally administered ocular corticosteroids and their benefits and risks. Drug Saf. 2002;25(1):33-55. 101:102/65/00002018-200225010-00004

14. Pavesio CE, DeCory HH. Treatment of ocular inflammatory conditions with loteprednol etabonate. $B r \quad J$ Ophthalmol. 2008;92(4):455-9. doi:10.1136/bjo.2007.132621.

15. Awan MA, Agarwal PK, Watson DG, McGhee CNJ, Dutton GN Penetration of topical and subconjunctival corticosteroids into human aqueous humour and its therapeutic significance. $\mathrm{Br} \mathrm{J}$ Ophthalmol. 2009;93(6):708-13. d01:10.1136/bj0.2008.154906.

16. Burke A, Smyth E, Fitzgerald GA. Analgesic antipyretic agents. In: Brunton LL, editor. Goodman and Gillman's Pharmacological Basis of Therapeutics. New Delhi: McGrew Hill; 2006. p. 671-716.

17. Solomon KD, Turkalj JW, Whiteside SB, Stewart JA, Apple DJ. Topical $0.5 \%$ Ketorolac vs $0.03 \%$ Flurbiprofen for the inhibition of miosis during cataract surgeries. Arch Ophthalmol. 1997;115:111922.

\section{Author biography}

Tek Chand, Senior Resident

Arvind Chauhan, Senior Professor \& Head

Cite this article: Chand T, Chauhan A. A comparative study of the efficacy of preoperative loteprednol versus flurbiprofen in cataract surgery. Indian J Clin Exp Ophthalmol 2020;6(4):581-586. 